\title{
Infestation of zooplankton with Triaenophorus and Proteocephalus procercoids (Cestoda) in a deep oligotrophic lake
}

\author{
Peter ANEGG, Roland PSENNER, Barbara TARTAROTTI* \\ University of Innsbruck, Institute of Ecology, Alpine Freshwater Ecology Division, Lake and Glacier Research Group, Technikerstraße \\ 25, 6020 Innsbruck, Austria \\ *Corresponding author: barbara.tartarotti@uibk.ac.at
}

\begin{abstract}
In spring 2004, a massive infestation of the whitefish population in the Austrian Lake Achensee with Triaenophorus crassus was observed. Procercoids, the larval stage of parasitic cestodes, infest copepods as their first intermediate host. Therefore, in spring 2011, zooplankton samples were taken weekly at two sampling sites and depth ranges to determine the abundances of crustaceans as well as percentages of infected copepods and temporal occurrence of parasites. In addition, whitefish (Coregonus lavaretus) stomach contents were analysed for food spectrum and parasite infestation. From the end of June to mid-August, procercoids of Triaenophorus spp. were detected in Cyclops abyssorum, the only first intermediate host for this parasite in Lake Achensee. Highest percentages of infected copepods were reached in mid-July (prevalence: 0.38\%). Furthermore, an infestation of Proteocephalus sp. was observed in this copepod species, which occurred earlier until the end of the sampling period (prevalence: $1.34 \%$ ). Besides C. abyssorum, also Eudiaptomus gracilis was occasionally infected with Proteocephalus (prevalence: $0.05 \%$ ). The procercoids were found in both depth ranges, with no clear vertical infestation preference. More C. abyssorum female were Triaenophorus-infected than males, while the opposite was observed for Proteocephalus infection. The whitefish stomachs contained large numbers of Proteocephalus and Triaenophorus procercoids, coinciding with the occurrence of these parasites in the copepods.
\end{abstract}

Key words: Parasites, tapeworms, Cyclops abyssorum, Eudiaptomus gracilis, Coregonus lavaretus.

Received: May 2014. Accepted: July 2014.

\section{INTRODUCTION}

Copepods can be hosts of several parasites, with microsporidians, nematodes and cestodes being the most commonly found taxa (Kurtz, 2007). Occurrences of the whitefish tapeworm Triaenophorus Rudolphi, 1793 (Cestoda: Pseudophyllidea) have been observed in Central and Western European (Brinker and Hamers, 2007), Scandinavian (Pasternak et al., 1999; Pulkkinen et al., 2000), as well as North American lakes (Ekbaum, 1935; Miller, 1952; Watson and Lawler, 1965; Hursky and Pietrock, 2012). Recently, these parasites have also been reported in some Austrian lakes (Lahnsteiner et al., 2009; Sichrowsky et al., 2013) where they caused epidemics in the Arctic charr (Salvelinus umbla) population (Achleitner et al., 2009; Schaufler et al., 2014). Members of the genus Triaenophorus have a complex three-host life cycle, with copepods as their first, planktivorous fish like coregonids as their second intermediate host, and pike (Esox lucius) as their definitive host (Kuperman, 1981). Infestations with Triaenophorus spp. are known to negatively affect the growth and condition of the second intermediate host (Rosen and Dick, 1984; Brinker and Hamers, 2007; Sichrowsky et al., 2013). For example, swimming activity was reduced and loss of equilibrium was observed in rainbow trout (Oncorhynchus mykiss), and increased mortality rates caused by muscle necrosis have been reported (Rosen and Dick, 1984). In addition, high infection rates have consequences for the fishery because sale or consumption of infected fish is prohibited although they do not present a danger for human health (Hursky and Pietrock, 2012). In our study site Lake Achensee, fishery played an important role for many centuries. In 2004, the commercial fishery had to be closed due to a $T$. crassus epidemic. In a preliminary study in 2010, six different fish species were infested with tapeworms. Triaenophorus crassus was found in the muscle tissue of coregonids (Coregonus lavaretus) and Arctic charr (Salvelinus umbla). Parasite cysts were also observed in the liver of some C. lavaretus and all European perch (Perca fluviatilis) examined, most probably belonging to Triaenophorus nodulosus. Pikes (Esox lucius) were infested with both Triaenophorus species.

Proteocephalus Weinland, 1858 (Cestoda: Proteocephalidae), another cestode commonly occurring in fishes of the Palearctic region (Scholz, 1999), causes no direct consequences for commercial fishery as this parasite stays in the fishes intestines. Although the parasite is considered relatively harmless when present only in small numbers, it affects its fish host, leading to reductions in growth and fitness (Priemer, 1987). Its life cycle is less 
complicated, with only one intermediate host, diaptomid or cyclopoid copepods (Scholz, 1999). This genus of cestodes has narrow host specificity, with different Proteocephalus species being specific to one fish genus or species. Proteocephalus longicollis (syn.: P. exiguus) is specific to salmonid fish such as coregonids or trout (Scholz, 1999). This species was also found in C. lavaretus during the preliminary study in 2010. Cestode parasites have been shown to improve the transmission to the next host by inducing both changes in the swimming activity and phototactic behaviour in infected copepods (Poulin et al., 1992; Pasternak et al., 1995; Pulkkinen et al., 2000). In the case of Triaenophorus infections, the copepods actively approach the water surface which increases the chance of being eaten by the second intermediate host (Pulkkinen et al., 2000). The fitness of infected copepods is also affected, for example, by increased mortality (Rosen and Dick, 1983; Pasternak et al., 1999) and decreased fecundity and feeding rates (Pasternak et al., 1999) in copepods infected with Triaenophorus procercoids. However, these findings seem to depend also on the infection intensity and duration of the experiments, as no effect on survival was shown in copepods when exposed to low parasite density and short exposure time (Shostak and Dick, 1986; Pasternak et al., 1995).

Several studies have addressed the morphology of Triaenophorus and Proteocephalus procercoids (Sysoev et al., 1994; Davydov et al., 1995) and factors determining their abundance in copepods under experimental conditions (Pasternak et al., 1999). Information on the occurrence and seasonal variation of procercoids under natural conditions, however, is still limited (Watson and Lawler, 1965; Sysoev, 1987; Hanzelova, 1992; Hanzelova and Gerdeaux, 2003). The aim of the present study was to estimate the period of appearance of cestode procercoids in copepod hosts and their infection rates in Lake Achensee, the largest lake in the federal state of Tyrol (Austria), subject to high cestode infestation in commercially important fish species over the last years. Moreover, we wanted to assess potential differences in copepod infection rates with sampling depth over two depth ranges. In addition, the stomach contents of planktivorous whitefish $(C$. lavaretus) were analysed over the course of the summer to follow changes in the diet of the fish along with preferences for infested copepods.

\section{METHODS}

\section{Investigation area}

The pre-alpine Lake Achensee (47 $26^{\prime} \mathrm{N}, 11^{\circ} 43^{\prime} \mathrm{E}, 929$ $\mathrm{m}$ asl) is a large (surface area: $\left.6.8 \mathrm{~km}^{2}\right)$, deep $\left(\mathrm{z}_{\max }, 133 \mathrm{~m}\right.$; $\mathrm{z}_{\text {mean }}, 67 \mathrm{~m}$ ), holomictic, oligotrophic (total phosphorous $<3 \mu \mathrm{g} / \mathrm{L}$ ), and cold lake with high Secchi depth (up to 11 $\mathrm{m}$ during the study period). Since 1927, the lake is ex- ploited for electric power generation which amounts to water level fluctuations of up to $\sim 6 \mathrm{~m}$ from October to May. From the literature it is known that infected copepods are not uniformly distributed over the whole lake (Watson and Lawler, 1965). In Lake Achensee, strong winds are frequent, which have the potential to influence the lateral transport of zooplankton as seen in other wind-exposed lakes (Thackeray et al., 2004). Pike (Esox lucius) spawn along the southern shoreline of this lake (A. Kandler, fisheries manager of Lake Achensee, personal communication). Thus, two sampling sites were chosen: Pertisau (N $\left.47^{\circ} 26.354^{\prime}, \mathrm{E} 11^{\circ} 42.673^{\prime}\right)$ is located in the southern part of the lake where it reaches its maximum width $\left(\mathrm{z}_{\max }, \sim 85\right.$ $\mathrm{m}$ ), while the second sampling site Gaisalm (N

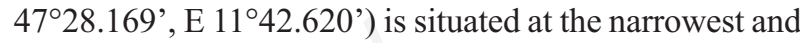
deepest part of the lake, where most of the fish (specifically $C$. lavaretus) stay (A. Kandler, personal communication). At both sites, pelagic gillnets were deployed several times during the course of the study (see below).

\section{Collection and processing of zooplankton}

Samples were taken weekly (except for the second sampling date) from 13 May until 24 August 2011 (i.e., 12 sampling dates) close to solar noon $(\sim 10: 00 \mathrm{~h}$ to 14:00 $\mathrm{h}$ local time). Zooplankton was sampled with a closing plankton net $(50 \mu \mathrm{m}$ mesh size $)$ over two depth ranges $(0$ $20 \mathrm{~m}$ and $20-50 \mathrm{~m}$ ) in triplicates. The samples were fixed with formalin (4\% final concentration). In addition, another set of samples (triplicates) was taken in both depth ranges to ensure a sufficient number of copepods for further determination of cestode infestation. The Secchi depth was measured, and temperature, $\mathrm{pH}$, and conductivity profiles (down to $20 \mathrm{~m}$ depth) were assessed with an YSI sensor (Monitoring Systems 610D, YSI Inc., Yellow Springs, OH, USA). In the laboratory, zooplankton (crustaceans) were counted according to species and ontogenetic life stages (nauplii, copepodid C1 to C5, adult female, egg-carrying female, and male copepods) in Bogorov chambers using a stereo microscope (Reichert, Vienna, Austria; 25-45× magnification). One 2-22 mL aliquot (depending on zooplankton density) out of $100 \mathrm{ml}$ total sample volume was analysed, as the within-sample variability ( 3 aliquots counted for 1 sample) was low (standard deviation $<5 \%$ ).

\section{Determination of copepod infestation with cestode procercoids}

For the determination of infested copepods, the formalin-fixed samples were rinsed with Milli-Q water and immersed in $80 \%$ glycerol $(\mathrm{v} / \mathrm{v})$ for $48 \mathrm{~h}$ to make the copepods more transparent. Between 100 and 515 (mean: $305)$ individual copepods per sample were examined under a stereo microscope and opened (when infested) 
with dissection needles to release the tapeworm larvae for a more detailed determination under an inverted microscope (Leitz Labovert, Leica Microsystems, Wetzlar, Germany; 40 to 640 -fold magnification). Because of their uniform morphology, molecular biological methods are necessary to identify the procercoids of the genus Triaenophorus to species-level (Boufana et al., 2011). In a fish survey taking place at the same time as the present study, the second intermediate hosts, C. lavaretus and $S$. umbla, were exclusively infested with $T$. crassus, while T. nodulosus was found in brown trout Salmo trutta (Schähle and co-workers, personal communication). As we cannot distinguish these cestodes at the species level, we will refer to Triaenophorus spp. throughout the text. The position of the lateral and apical suckers in the procercoids of Proteocephalus, together with the narrow host specificity of this tapeworm genus (Scholz, 1999), and findings of Proteocephalus longicollis in C. lavaretus in a preliminary study in 2010 , suggest that the species observed in copepods from Lake Achensee is Proteocephalus longicollis. However, as we cannot exclude the presence of other Proteocephalus species, we will refer to Proteocephalus sp. throughout the text. The percentage of infestation (prevalence) in the copepods was determined. Altogether, 20,730 copepods (14656 Cyclops abyssorum and 6074 Eudiaptomus gracilis, respectively) were examined.

\section{Fish stomach content analysis}

Out of 222 whitefish (C. lavaretus), 43 individuals were chosen for stomach content analysis. The fish were caught with pelagic gillnets (10 to $43 \mathrm{~mm}$ mesh size, knot to knot) in the neighbourhood of the two sampling sites Gaisalm and Pertisau between June and July 2011. The nets were deployed in a depth down to $\sim 20 \mathrm{~m}$ where most of the whitefish stay (Schähle et al., personal communication). The choice of the 43 individuals was made based on the temporal proximity ( \pm 1 day from zooplankton sampling) and comparable fish size and weight, respectively. The fish intestines were fixed in $70 \%$ ethanol, and ethanol was also directly injected into each stomach to stop further digestion. After opening the stomachs, their fullness was estimated and the different food items identified and counted. Depending on the quantity and condition of the stomach contents, either the entire sample or one 5-25 ml aliquot ( 5 to $25 \mathrm{~mL}$ out of $100 \mathrm{~mL}$ total sample volume) were analysed. The prey items from the stomachs of all fish were pooled, and then the percentage of each prey species was calculated. For further comparison of the food spectrum, the coregonids investigated were classified in two size groups $(15-25 \mathrm{~cm}$ and $25-32 \mathrm{~cm})$. In addition, fish were grouped based on the month in which they were caught (June and July) to observe temporal changes in the food spectrum.

\section{Data treatment}

Data for crustacean abundance are reported as mean \pm standard deviation. Differences in the percentage of infested C. abyssorum between sampling depths were tested by Wilcoxon signed rank tests.

\section{RESULTS}

\section{Diversity and abundance of crustaceans}

The zooplankton species diversity in Lake Achensee was low; two copepod species (Cyclops abyssorum and Eudiaptomus gracilis) and three cladoceran species occurred during the study period. Higher zooplankton abundances were found at the northern sampling site Gaisalm, with up to $\sim 14$ individuals $\mathrm{L}^{-1}$ (total number of crustaceans) in midJune, compared to the sampling site Pertisau with up to 11 individuals $\mathrm{L}^{-1}$ (end of June) (Fig. 1). The cladocerans Daphnia hyalina and Bosmina longispina were the dominant species (up to 5.8 individuals $\mathrm{L}^{-1}$, mean $1.1 \pm 1.5$ and 5.1 individuals $\mathrm{L}^{-1}$, mean $0.8 \pm 1.2$, respectively), while only small numbers of $C$. abyssorum (up to 2.4 individuals $\mathrm{L}^{-1}$, mean $0.7 \pm 0.5$; copepodid C1-adults) and E. gracilis (up to 1.1 individuals $\mathrm{L}^{-1}$, mean $0.3 \pm 0.3$; copepodid $\mathrm{C} 1$-adults) were found (Fig. 1). Both copepod species showed highest abundances between mid-June to mid-July (Fig. 1). Nauplii were present during the whole study period at both sites and depth ranges (up to 4.6 individuals $\mathrm{L}^{-1}$, mean $1.54 \pm 0.9$ ), whereas the cladoceran Leptodora kindtii was less frequently found in the samples (up to 0.06 individuals $\mathrm{L}^{-1}$, mean $0.01 \pm 0.01$ ). For both sites and all sampling dates, the main distribution of the crustaceans was always in the upper 20 meters (Fig. 1).

\section{Infection of copepods with procercoids}

Cyclops abyssorum was the only first intermediate host of Triaenophorus spp. The procercoids were found in the body cavity of this copepod species from 21 June to 11 August, 2011 and appeared one week earlier in the northern part (Gaisalm) than in the southern part (Pertisau) of the lake (Fig. 2). The prevalence of Triaenophorus procercoids in C. abyssorum was $0.38 \%$ (56 infected copepods out of 14656 examined), the maximum infection rate $(3.7 \%)$ was reached on 19 July at Pertisau in the upper sampling depth (Fig. 2). The mean percentage of infected copepods for both sampling sites and depths, where Triaenophorus procercoids were present in the copepods, was $0.6 \%$. The spatiotemporal appearance of Proteocephalus sp. showed a different pattern. This cestode was already found in C. abyssorum on 7 June and was present during the whole sampling period (Fig. 2). Out of the 14,656 examined copepods, 197 were infected with Proteocephalus procercoids (prevalence: 1.34\%). On 11 August, the maximum infection rate was observed with 

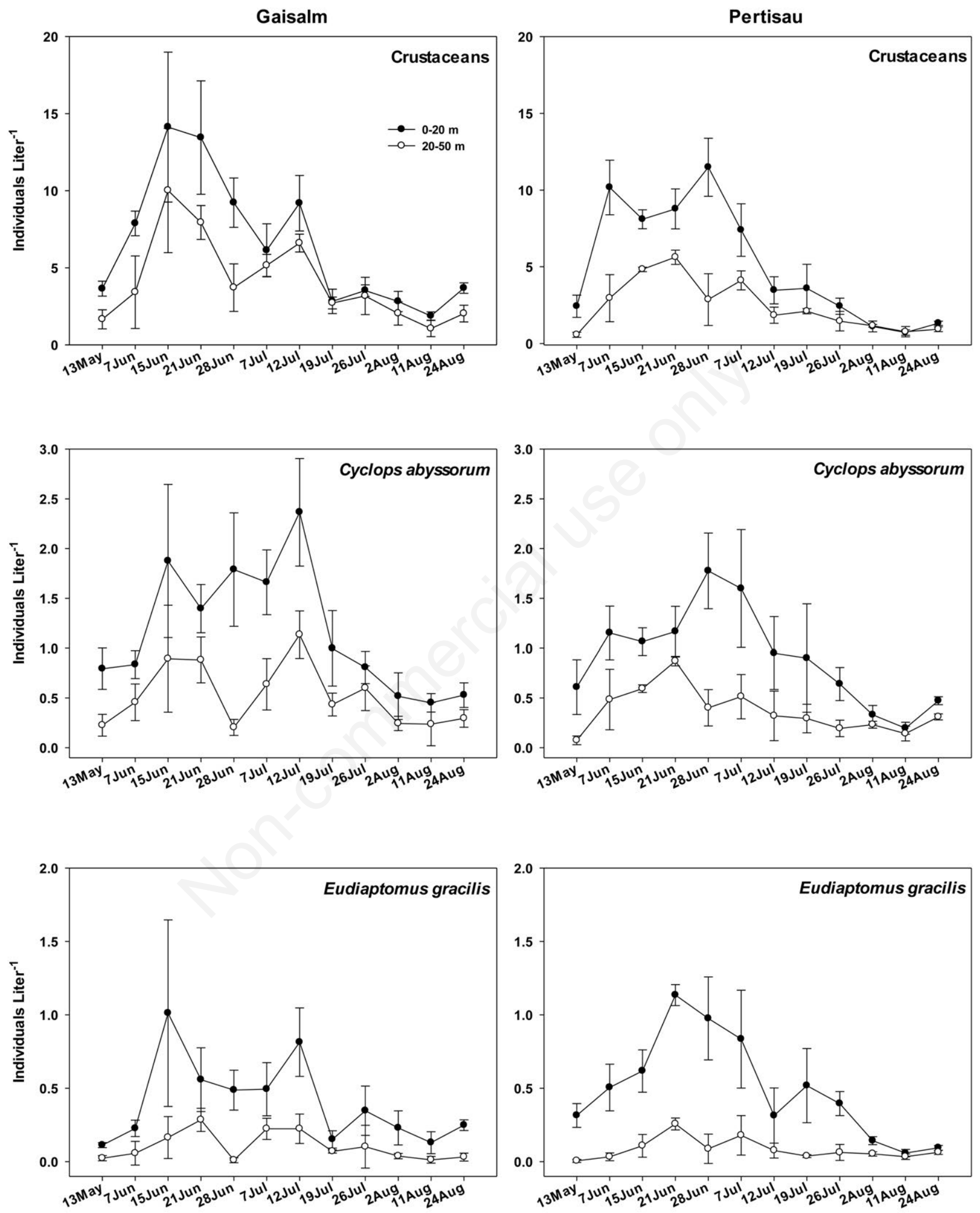

Date

Date

Fig. 1. Abundances of crustaceans, C. abyssorum (copepodid CI to adult), and E. gracilis (copepodid CI to adult) at sampling sites Gaisalm and Pertisau in Lake Achensee. 
$10.0 \%$ infected C. abyssorum (Fig. 2). On average, the percentage of infected copepods was $2.2 \%$ over the infestation period for both sampling sites and depths. The percentage of infected $C$. abyssorum did not differ significantly (Wilcoxon signed rank test, $\mathrm{P}>0.05$ ) between the different sampling depths, the different sampling sites or between the cestode genera. Rarely, also the copepod E. gracilis was infested with Proteocephalus procercoids (prevalence, $0.05 \%$; maximum infection rate, 1.5\%, 26 July, 2011; Gaisalm, 20-50 m depth range), but no Triaenophorus procercoids were found in this calanoid copepod species. Highest infection rates of Triaenophorus spp. were found when the water temperature in the upper zone $(0-20 \mathrm{~m})$ was between $12.5^{\circ}$ and $14^{\circ} \mathrm{C}$ (Fig. 3A), while Proteocephalus procercoids appeared already at lower water temperatures $\left(\sim 11^{\circ} \mathrm{C}\right)$ (Fig. 3B).

\section{Life stage-specific copepod infestation and multiple infested copepods}

The highest percentage of Triaenophorus infestation was found in adult females (out of 56 infested copepods, 16 and 22 were females or egg-carrying females, respectively), followed by adult males, and copepodid C5 life stages of C. abyssorum (Tab. 1). No Triaenophorus procercoids were observed in younger developmental stages. The youngest life stage of $C$. abyssorum infested with Proteocephalus sp. was copepodid C4. Most procercoids of Proteocephalus sp. were found in adult males (70 out of 197 infested C. abyssorum), followed by copepodid C5, and adult females (Tab. 1). The three individuals of E. gracilis infested with procercoids of Proteocephalus sp. were a copepodid C5, female, and male. Multiple in-
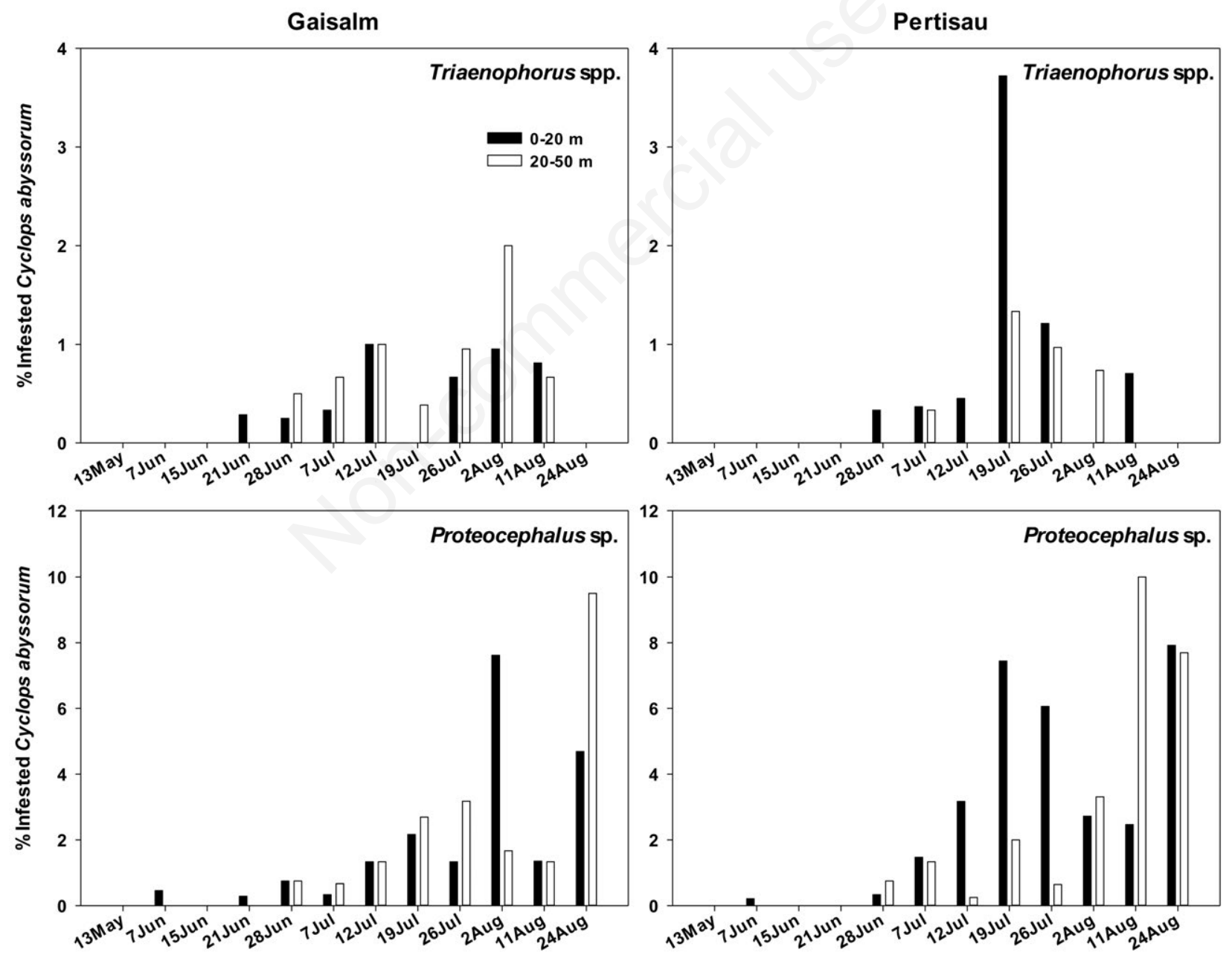

Date

Date

Fig. 2. Percentage of C. abyssorum infected with procercoids of Triaenophorus spp. and Proteocephalus sp. at sampling sites Gaisalm and Pertisau in Lake Achensee. 
festations were found in $\sim 5 \%$ of the infested copepods (Tab. 1). The maximum number was three procercoids of Proteocephalus sp. in the body cavity of one adult female, and two procercoids of Triaenophorus spp. in another female $C$. abyssorum. In one case, one individual was infested with both Triaenophorus spp. and Proteocephalus sp. procercoids at the same time (19 July, upper sampling depth at Pertisau). There was no case of multiple infestations in E. gracilis.

\section{Fish stomach contents}

Overall, D. hyalina $(71.2 \%)$ was the dominant prey item in the fish stomachs examined $(\mathrm{n}=43)$, followed by B. longispina $(17.6 \%)$, C. abyssorum (5.6\%) and Leptodora kindtii $(5.1 \%)$. Based on temporal changes, in June, the food spectrum of the coregonids was dominated by $B$. longispina, which showed high abundances in the water column at this time, followed by D. hyalina and $C$. abyssorum (Fig. 4). The predatory cladoceran L. kindtii, chironomids, other insects and molluscs were occasionally found in the fish stomachs. In July, the relative distribution of the food spectrum clearly differed and was dominated by $D$. hyalina, while the other cladocerans were less frequently eaten by $C$. lavaretus. Compared to June, $C$. abyssorum made only a small percentage of the stomach content in July (Fig. 4). When calculated for different fish size ranges, $C$. abyssorum accounted for $1.9 \%$ of the diet in the $15-25 \mathrm{~cm}$ and $12.8 \%$ in the $25-30 \mathrm{~cm}$ length class, respectively. Both $C$. lavaretus length classes mainly fed on D. hyalina ( $87.3 \%$ and $42.3 \%$, respectively) and $B$. longispina ( $10.4 \%$ and $32.0 \%$, respectively).

Many free tapeworm larvae were found in the partly digested stomach contents (Tab. 2). In early June (09 June, 2011), the stomach of a coregonid (28.7 cm length, 190.8 g weight) contained 312 Proteocephalus procercoids, and up to 36 Triaenophorus procercoids were observed in another whitefish at the end of July (26 July, 2011; $32.1 \mathrm{~cm}$ length, $281.2 \mathrm{~g}$ weight) (Tab. 2). Highest numbers of free tapeworm larvae were found in the largest whitefish (25$32 \mathrm{~cm}$ ) examined (Fig. 5).

Triaenophorus procercoids in the whitefish stomachs appeared the first time at the end of June (30 June 2011) and were present in the stomachs from that date on, while Proteocephalus procercoids were found already on the first sampling date (7 June 2011) in high numbers. These findings reflect the temporal appearance of the parasites in the open water column (Fig. 2).

\section{DISCUSSION}

The cyclopoid copepod C. abyssorum was the only first intermediate host of the cestode Triaenophorus spp. in Lake Achensee. Apart from C. abyssorum, the calanoid copepod E. gracilis was infested in low numbers with pro-
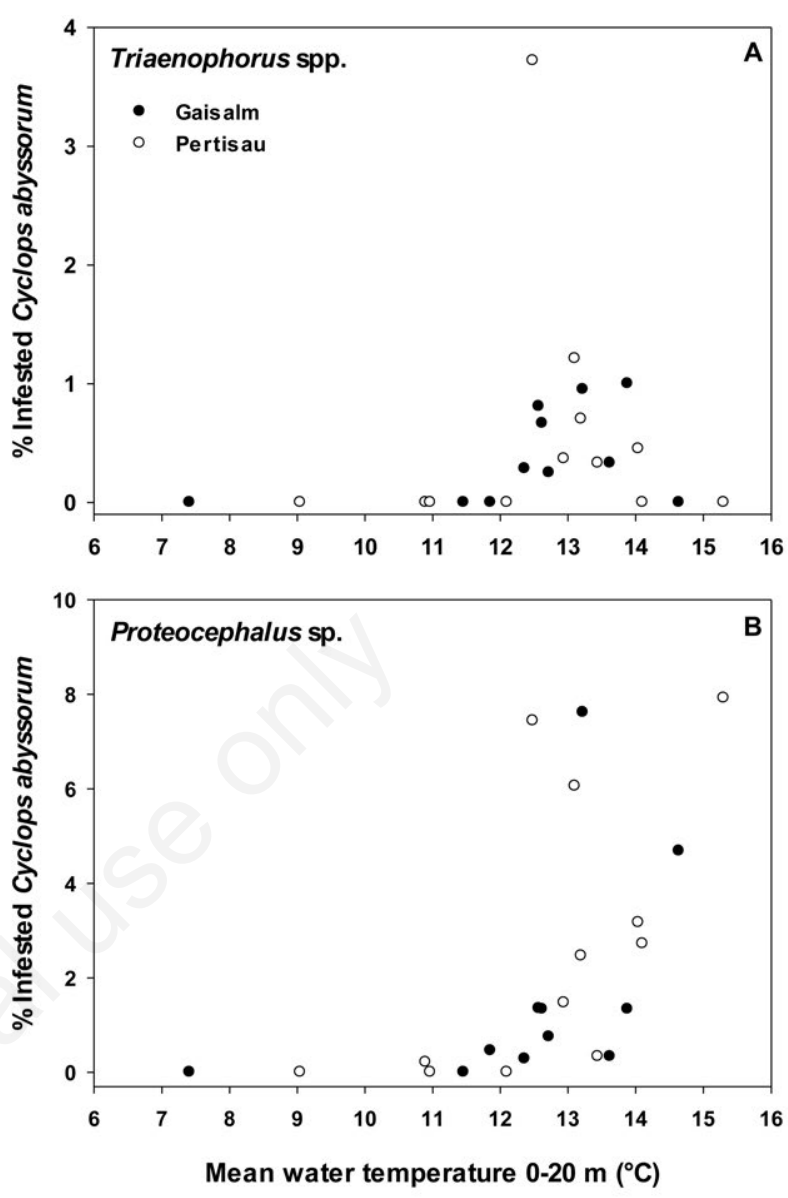

Fig. 3. Relationship between water temperature and percentage of Cyclops abyssorum infected with Triaenophorus and Proteocephalus procercoids at sampling sites Gaisalm and Pertisau in Lake Achensee.

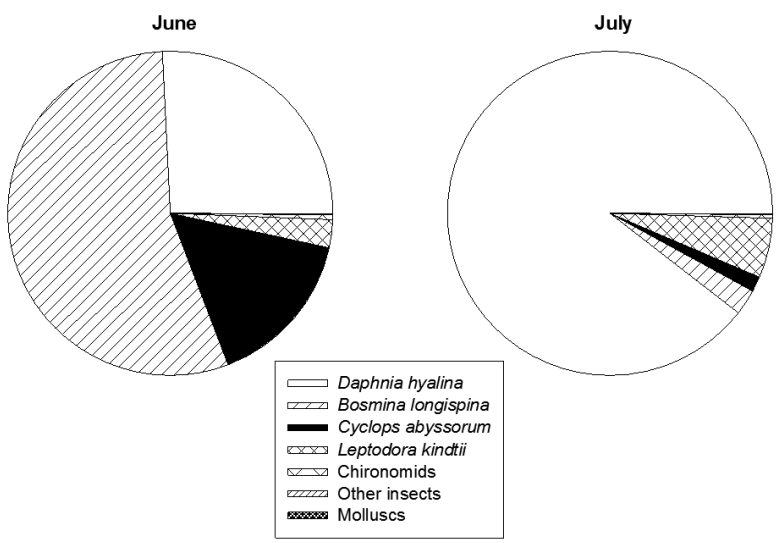

Fig. 4. Relative proportion in percentage of food found in whitefish (C. lavaretus) stomachs from Lake Achensee for the months June (left) and July (right) ( $\mathrm{n}=19$ for June and n=24 for July). 
cercoids of Proteocephalus sp., most likely P. longicollis. This coincides with findings from the literature, where cyclopoid copepods were found to be the first intermediate hosts of both T. crassus and T. nodulosus, with Cyclops vicinus and C. abyssorum (misidentified as C. strenuus) being the most important first intermediate hosts of $T$. crassus in European freshwater systems (Kuperman, 1981). In total, 21 cyclopoid vs 3 calanoid copepod species are known to be infested with T. crassus (Marcogliese, 1995). In the Austrian Lake Fuschlsee, one single Triaenophorus procercoid out of 140 was found in an E. gracilis individual, while the remaining procercoids were observed in $C$. abyssorum (Sichrowsky et al., 2013). Although all $C$. lavaretus and $\sim 16 \%$ of $S$. umbla investigated in Lake Achensee were infested with $T$. crassus (Schähle et al., $2014)$, the prevalence of the parasites was low $(0.38 \%$; maximum infection rate, $3.7 \%$; Fig. 2), but comparable to studies from several lakes in Austria (Lahnsteiner et al., 2009; Sichrowsky et al., 2013; Schaufler et al., 2014), France (Hanzelova and Gerdeaux, 2003) or Canada (Watson and Lawler, 1965). In Lake Fuschlsee, for example, up to $\sim 2 \%$ (mean $0.4 \%$ ) of the C. abyssorum population were infested with Triaenophorus procercoids (Sichrowsky et al., 2013). The high infection rate reported in Lake Mondsee (up to 38.7\%) could be explained by the determination technique of the procercoids, as the parasites were counted without distinguishing different cestode genera (Lahnsteiner et al., 2009). In Lake Achensee, the prevalence of Proteocephalus infection was relatively high $(1.34 \%)$, however, the maximum total cestode infection rate made up to $\sim 11 \%$, with an infestation peak reached in mid-July (Fig. 2), which is considerably lower than the maximum infection rate found in C. abyssorum from Lake Mondsee.
In general, the period of appearance of the parasites is closely related to the water temperature. Northern pikes (E. lucius) are known to spawn in early spring, between March and April, at lake water temperatures reaching $6^{\circ} \mathrm{C}$ and over (Frost and Kipling, 1967). In Lake Achensee, local fishermen observed the first pikes spawning at the end of May 2011 (A. Kandler, personal communication). At this time of the year, the water temperature in the vicinity of the southern sampling site Pertisau was $13.4^{\circ} \mathrm{C}(0.5$ $\mathrm{m}$ depth, close to the shoreline; A. Kandler, personal communication). The developmental time from the egg to the coracidia larvae is temperature-dependent and usually

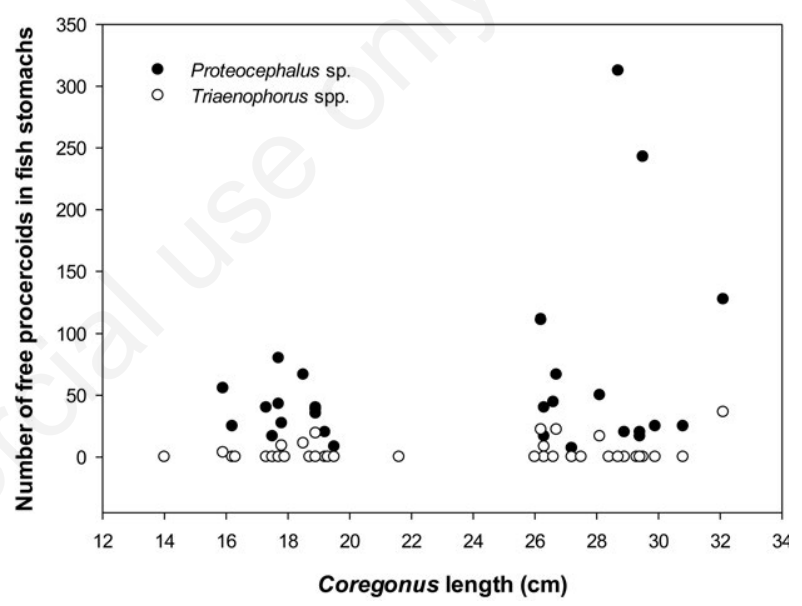

Fig. 5. Relationship between fish length (C. lavaretus) and number of free Proteocephalus and Triaenophorus procercoids found in whitefish stomachs from Lake Achensee.

Tab. 1. Life stage specific infestation of C. abyssorum with procercoids of Triaenophorus spp. and Proteocephalus sp., total number of studied C. abyssorum, percentage of infected C. abyssorum, and multiple infestations in Lake Achensee.

\begin{tabular}{lcccccccc}
\hline Cyclops abyssorum & $\begin{array}{c}\mathrm{C} 4 \\
(\%)\end{array}$ & $\begin{array}{c}\mathrm{C} 5 \\
(\%)\end{array}$ & $\begin{array}{c}\text { Females } \\
(\%)\end{array}$ & $\begin{array}{c}\text { Females with eggs } \\
(\%)\end{array}$ & $\begin{array}{c}\text { Males } \\
(\%)\end{array}$ & $\begin{array}{c}\text { Total number of } \\
\text { studied Cyclops }\end{array}$ & $\begin{array}{c}\text { Percentage of } \\
\text { infected Cyclops }\end{array}$ & $\begin{array}{c}\text { Multiple infestation } \\
\text { (total Cyclops) }\end{array}$ \\
\hline Triaenophorus spp. & 0.0 & 14.3 & 28.6 & 39.3 & 17.8 & 14,656 & 0.38 & 0.8 \\
Proteocephalus sp. & 5.6 & 31.0 & 25.4 & 2.5 & 35.5 & 14,656 & 1.34 & 4.4 \\
\hline
\end{tabular}

C4, copepodid life stage C4; C5, copepodid life stage C5.

Tab. 2. Free procercoids (mean \pm standard deviation and maximum) found in stomachs of whitefish (Coregonus lavaretus) from Lake Achensee during the months of June and July. Numbers of fish are as in Fig. 4.

\begin{tabular}{lcccc}
\hline & & & & July \\
& Triaenophorus spp. & Proteocephalus sp. & Triaenophorus spp. & Proteocephalus sp. \\
\hline Mean & $1.6( \pm 5.3)$ & $49.5( \pm 86.3)$ & $4.9( \pm 9.6)$ & $28.4( \pm 31.0)$ \\
Max & 22.2 & 312.5 & 36.4 & 127.3 \\
\hline
\end{tabular}


takes between two to six weeks (Kuperman, 1981). In fact, the first copepods infested with Triaenophorus spp. were found three weeks after the observed spawning of pike (21 June 2011; Fig. 2). This is relatively late in the year compared to the first procercoid occurrence in other Austrian lakes (from mid-May to beginning of June; Lahnsteiner et al., 2009; Sichrowsky et al., 2013; Schaufler et al., 2014), but corresponds with the lower water temperature found in our study system. In Lake Achensee, highest infection rates of Triaenophorus spp. were found when the water temperature in the upper zone was between $12.5^{\circ} \mathrm{C}$ and $14^{\circ} \mathrm{C}$ (Fig. 3A). In comparison, Proteocephalus $\mathrm{sp}$. procercoids appeared already at lower water temperatures $\left(10.9^{\circ} \mathrm{C}\right)$ earlier in the year $(7$ June 2011; Fig. 3B). Although the first appearance may differ inter-annually and from lake to lake, the highest number of Proteocephalus sp. infestations was still observed in the summer months July and August (Fig. 2). These findings are in accordance with other studies where highest rates of copepod infections were found in late spring and summer (Sysoev, 1987; Marcogliese, 1995; Hanzelova and Gerdeaux, 2003).

Due to parasite-controlled changes in the phototactic behaviour of the first intermediate host (Pulkkinen et al., 2000), we expected to find more infested copepods in the upper depth range of the two sampling depth ranges. Although the abundances of both copepod species were always higher in the upper sampling depth (Fig. 1), there was no clear trend in the infection rate for depth range (Fig. 2). Interestingly, the first appearance of both parasites was in the upper depth range at both sampling sites (Fig. 2). The maximum Triaenophorus spp. infestation was also found in the upper depth range at Pertisau (Fig. 2), but in the lower one at Gaisalm (Fig. 2). We are aware that the depth ranges that we sampled are broad, and that the observations from Pulkkinen et al. (2000) derive from laboratory experiments using a defined, small water column $(40 \mathrm{~cm}$ height), while in the open water column copepods can move freely (vertical and horizontal migrations). Nevertheless, it would be interesting to follow the vertical distribution (both during the day and night) of infected copepods over several discrete depths to receive a more detailed picture of potential changes in the host behaviour in nature. In addition, the occurrence of infected copepods may be higher in near-shore shallow water areas (Watson and Lawler, 1965). In Lake Achensee, however, the most important second intermediate host, planktivorous $C$. lavaretus, is distributed over the whole lake without a preference for shallow areas close to the shore (A. Kandler, personal communication). The density of copepods is among the factors influencing the proportion of copepods becoming infected with cestodes such as Proteocephalus (Marcogliese, 2001; Hanzelova and Gerdeaux, 2003). This could explain why the percentage of infected
C. abyssorum was $\sim 35$-fold higher when compared with E. gracilis infections, as the former copepod species is always more abundant in Lake Achensee (Fig. 1). Moreover, cyclopoid copepods are considered to be omni/carnivore and feed raptorially, which might further affect the capacity of transmission (Marcogliese, 1995). Despite the similar appearance and size range of pseudophyllidean coracidia and ciliates, which serve as food source for crustaceans like copepods (Wiackowski et al., 1994), only little work has been done to examine whether copepods can distinguish between prey items or not and how the parasite uptake is affected by other food (Pasternak et al., 1999). A selective consumption of coracidia, however, could not be proven by the study of Pasternak et al. (1999).

Our results show a higher infection rate with Triaenophorus procercoids in female copepods than in males (Tab. 1). While the opposite was found for C. abyssorum from Lake Fuschlsee (Sichrowsky et al., 2013), our findings agree with those of Pasternak et al. (1999) reported for Proteocephalus infestation. These authors argue that due to the smaller size and slower swimming speed of male $C$. abyssorum they might be exposed less frequently to coracidia larvae than the bigger female individuals. For Proteocephalus, the life stage-specific copepod infestation showed a more balanced infection rate, however, more males than females were infested with procercoids (Tab. 1). In comparison to other studies, female C. abyssorum prealpinus were reported to be three times more often Proteocephalus-infested than males (Hanzelova and Gerdeaux, 2003). In addition, sex-specific differences in the vertical distribution of copepods (Schabetsberger and Jersabek, 2004) might further influence the life stage-specific copepod infestation. Since Triaenophorus and Proteocephalus share the same first intermediate host, it is likely that copepods get infested not only with one but with different cestodes at the same time. In our study, a multiple infestation with both parasites was found only once, while multiple infestations with one of the two cestode genera were observed several times throughout the study (Tab. 1). Such multiple infections have been also observed in C. abyssorum prealpinus with up to four procercoids of $P$. longicollis present in the copepods (Hanzelova and Gerdeaux, 2003).

Behavioural changes (e.g., decreased swimming activity) of infested copepods improve the transmission to the next host, making them easy prey for fish (Pulkkinen et al., 2000). In the Austrian Lake Grundlsee, the infection rate of copepods found in fish stomachs ( $S$. umbla and Coregonus spp.) was 170 times higher than those in the water column (Schabetsberger et al., 2008). In Lake Achensee, fish were caught using gill nets, which were deployed overnight. As digestion is known to be relatively fast in whitefish (Hofer, 1987), only relatively few cope- 
pods present in the whitefish stomachs were completely intact. For this reason, and because of the relatively low number of copepods present in the fish stomachs, it was not possible to determine if the copepods present in the fish stomachs showed a higher prevalence in comparison with the water column. Nevertheless, many free Triaenophorus and Proteocephalus procercoids were found in the fish stomachs (Tab. 2), giving clear evidence that infested copepods get eaten by whitefish in large numbers. Not only procercoids, morphologically corresponding to the procercoids found in the copepods, but also a high number of young tapeworms without segmentation of the genus Proteocephalus were observed in the stomachs. Similar observations were made in whitefish $(C$. lavaretus) from the French Lake Annecy where the number of $P$. longicollis isolated from pyloric caeca and the anterior small intestine reached up to 500 individuals per fish (Hanzelova and Gerdeaux, 2003). Since larger fish have had greater exposure to parasites, as they feed more and on a greater diversity of prey, it is not surprising that the highest numbers of free procercoids were found in the largest fish (Fig. 5).

\section{CONCLUSIONS}

Overall, the results of the present study show that the copepod C. abyssorum plays an important role for the transmission of cestodes, as it is the unique or predominant zooplankton species infected with Triaenophorus and Proteocephalus procercoids. It is mostly adult life stages of $C$. abyssorum that get infected with the tapeworms, with no clear vertical infestation preference over two depth ranges. Although the portion of copepods in the diet of the whitefish $C$. lavaretus was relatively small, high numbers of procercoids were found in the fish stomachs, suggesting that many infected copepods get eaten by the coregonids in Lake Achensee. Climate change, especially temperature change and its associated changes in other parameters, can potentially lead to alterations in the parasite fauna and host distribution, thereby also affecting parasite transmission (Marcogliese, 2001). Besides these changes, also artificial modifications can have effects on the transmission from copepod to fish, for instance, the destruction of the littoral zone in the course of reservoir building that forces the whitefish to shift their diet towards copepods (Petersson, 1971; Marcogliese, 1995), which may result in the accumulation of parasites. In Lake Achensee, water level fluctuations might affect the feeding behaviour of whitefish and subsequent parasite infestation at least to some extent. Changes in physical processes, but also biological factors such as high abundances of the final host, pike, may have led to the increased occurrence of tapeworm infections as observed in Lake Achensee and other Austrian pre-alpine lakes (Achleitner et al., 2009; Schaufler et al., 2014) over the last years.

\section{ACKNOWLEDGMENTS}

We thank Anton Kandler, Rosa Schwer, Philipp Kirschner, Georg Kandolf, Katharsina Podliesikova, Sandra Liedke, Georg Anegg, Philipp Efinger, Florian Hofer, Susanne Tatzl, and Hubert Heis for field assistance, and Josef Franzoi for his technical help in the laboratory. We greatly acknowledge Zacharias Schähle for providing fish stomachs. We are grateful to Anton Kandler, Nikolaus Medgyesy, Zacharias Schähle, and Ursula Sichrowsky for helpful discussions. This work was supported by the Tiroler Wasserkraft AG (TIWAG) and the City of Innsbruck.

\section{REFERENCES}

Achleitner D, Gasser H, Schabetsberger R, 2009. Global Worming: first record of an epidemic of Triaenophorus crassus in a population of Artic charr Salvelinus umbla. J. Fish Biol. 74:961-966.

Boufana B, Žibrat U, Jehle R, Craig P, Gassner H, Schabetsberger R, 2011. Differential diagnosis of Triaenophorus crassus and T. nodulosus experimental infection in Cyclops abyssorum praealpinus (Copepoda) from the Alpine Lake Grundlsee (Austria) using PCR-RFLP. Parasitol. Res. 109:745-750.

Brinker A, Hamers R, 2007. Evidence for negative impact of plerocercoid infection of Triaenophorus nodulosus on Perca fluviatilis L. stock in Upper Lake Constance, a water body undergoing rapid reoligotrophication. J. Fish Biol. 71:129-147.

Davydov VG, Korneva JV, Kuperman BI, 1995. The development of the tegument in ontogenesis of Triaenophorus nodulosus (Cestoda: Pseudophyllidea). Folia Parasit. 42:269-279.

Ekbaum E, 1935. Notes on the Species of Triaenophorus in Canada. J. Parasitol. 21:260-263.

Frost WE, Kipling C, 1967. A study of reproduction, early life, weight-length relationship and growth of pike, Esox lucius, L., in Windermere. J. Anim. Ecol. 36:651-693.

Hanzelova V, 1992. Proteocephalus neglectus as a possible indicator of changes in the ecological balance of aquatic environments. J. Helminthol. 66:17-24.

Hanzelova V, Geredeaux D, 2003. Seasonal occurrence of the tapeworm Proteocephalus longicollis and its transmission from copepod intermediate host to fish. Parasitol. Res. 91:130-136.

Hofer R, 1987. [Verdauungsstrategien bei Fischen].[Article in German]. Biol. Unserer Zeit 17:84-89.

Hursky O, Pietrock M, 2012. Chemical contaminants and parasites: Assessment of human health risks associated with consumption of whitefish (Coregonus clupeaformis) from two boreal lakes in northern Saskatchewan, Canada. Sci. Total Environ. 424:97-103.

Kuperman BI, 1981. Tapeworms of the genus Triaenophorus, parasites of fishes. Amerind Pub., New Delhi, India: 222 pp.

Kurtz J, 2007. Evolutionary ecology of immune defence in copepods. J. Plankton Res. 29:i27-i38.

Lahnsteiner F, Kletzl M, Weismann T, 2009. The risk of parasite transfer to juvenile fishes by live copepod food with the example Triaenophorus crassus and Trianeophorus nodulosus. Aquaculture 295:120-125. 
Marcogliese DJ, 1995. The role of zooplankton in the transmission of helminth parasites to fish. Rev. Fish Biol. Fisher. 5:336-371.

Marcogliese DJ, 2001. Implications of climate change for parasitism of animals in the aquatic environment. Can. J. Zool. 79:1331-1352.

Miller RB, 1952. A review of the Triaenophorus problem in Canadian lakes. B. Fish. Res. Board Can. 95:1-42.

Pasternak AF, Huntingford FA, Crompton DWT, 1995. Changes in metabolism and behaviour of the freshwater copepod $C y$ clops strenuus abyssorum infected with Diphyllobothrium spp. Parasitology 110:395-399.

Pasternak AF, Pulkkinen K, Mikheev VN, Hasu T, Valtonen ET, 1999. Factors affecting abundance of Triaenophorus infection in Cyclops strenuus, and parasite-induced changes in host fitness. Int. J. Parasitol. 29:1793-1801.

Petersson A, 1971. The effect of lake regulation on populations of Cestodan parasites of Swedish whitefish Coregonus. Oikos 22:74-83.

Poulin R, Curtis MA, Rau ME, 1992. Effects of Eubothrium salvelini (Cestoda) on the behaviour of Cyclops vernalis (Copepoda) and its susceptibility to fish predators. Parasitology 105:265-271.

Priemer J, 1987. On the life cycle of Proteocephalus exiguus (Cestoda) from Salmo gairdneri (Pisces). Helminthologia 24:75-85.

Pulkkinen K, Pasternak AF, Hasu T, Valtonen ET, 2000. Effect of Triaenophorus crassus (Cestoda) infection on behaviour and susceptibility to predation of the first intermediate host Cyclops strenuus (Copepoda). J. Parasitol. 86:664-670.

Rosen R, Dick TA, 1983. Development of the procercoid of Triaenophorus crassus Forel and mortality of the first intermediate host. Can. J. Zool. 61:2120-2128.

Rosen R, Dick TA, 1984. Experimental infections of rainbow trout, Salmo gairdneri Richardson, with plerocercoids of Triaenophorus crassus Forel. J. Wildlife Dis. 20(1):34-38.

Schabetsberger R, Achleitner D, Gassner H, Žibrat U, 2008. [Untersuchung der Hechtbandwurmepidemie des Seesaiblingbestandes im Grundlsee: Endbericht der Vorstudie].[Book in German]. University of Salzburg, Austria.

Schabetsberger R, Achleitner D, Gassner H, Žibrat U, 2008. [Un- tersuchung der Hechtbandwurmepidemie des Seesaiblingbestandes im Grundlsee: Endbericht der Vorstudie].[Book in German]. University of Salzburg, Austria.

Schähle Z, Medgyesy N, Psenner R, 2014. Infection levels of plerocercoids of the tapeworm Triaenophorus crassus and feeding strategy in two fish species from the ultra-oligotrophic Lake Achensee, Austria. J. Helminthol. [Epub ahead of print]. doi:10.1017/S0022149X1400077.

Schaufler G, Stögner C, Achleitner D, Gassner H, Žibrat U, Kaiser R, Schabetsberger R, 2014. Translocated Esox lucius L. (PISCES) trigger a Triaenophorus crassus forel (CESTODA) epidemic in a population of Salvelinus umbla (L.) (PISCES). Int. Rev. Hydrobiol. 99:1-13.

Scholz T, 1999. Life cycles of species of Proteocephalus parasites of fishes in the Palearctic Region: a review. J. Helminthol. 73:1-19.

Shostak AW, Dick TA, 1986. Effect of food intake by Cyclops bicuspidatus thomasi (Copepoda) on growth of procercoids of Triaenophorus crassus (Pseudophyllidea) and on host fecundity. Am. Midl. Nat. 115:225-233.

Sichrowsky U, Schabetsberger R, Gassner H, Kaiser R, Boufana B, Psenner R, 2013. Cradle or plague pit? Illuminated cages increase the transmission risk of parasites from copepods to coregonids. Aquaculture 392-395:8-15.

Sysoev AV, 1987. Seasonal dynamics of invasion of copepods with procercoids of cestodes in small lakes of Karelia. Angewandte Parasitologie 28:191-204.

Sysoev AV, Freze VI, Andersen KI, 1994. On the morphology of procercoids of the genus Proteocephalus (Cestoda, Proteocephalidea). Parasitol. Res. 80:245-252.

Thackeray SJ, George DG, Jones RI, Winfield IJ, 2004. Quantitative analysis of the importance of wind-induced circulation for the spatial structuring of planktonic populations. Freshwater Biol. 49:1091-1102.

Watson NHF, Lawler GH, 1965. Natural infections of cyclopoid copepods with procercoids of Triaenophorus spp. at Heming Lake, Manitoba. Fish. Res. Board Can. 22:1335-1338.

Wiackowski K, Brett M, Goldman CR, 1994. Differential effects of zooplankton species on ciliate community structure. Limnol. Oceanogr. 39:486-492. 